\title{
The results of the clinical trials in hypertension: unquestionable benefits and limits
}

\begin{abstract}
Lowering blood pressure is the main target to achieve for reducing cardiovascular complications in hypertensive patients. Large-scale trials have been conducted to identify the best way to do it by using drugs and preventive measures. Although these studies give some benefits in term of control of the elevated blood pressure, some limits still exist because a very effective treatment useful for all individuals has been not found.
\end{abstract}

Keywords: clinical trials, hypertension, hypertension-related disorders, cardiovascular complications
Volume 9 Issue 3 - 2017

\author{
Aurelio Leone $e^{1,2,3}$ \\ 'Fellow of the American Society of Hypertension (FASH), USA \\ ${ }^{2}$ Fellow of the Royal Society for Promotion of Health (FRSPH), \\ UK \\ ${ }^{3}$ Editor-in-Chief, Journal Cardiology \& Current Research, USA
}

Correspondence: Aurelio Leone,Via Provinciale 27, 19030 Castelnuovo Magra, Italy, Email reliol@libero.it

Received: February 21, 2017| Published: July 21, 2017

\section{Introduction}

Current opinion is the main trials analyzing the results obtained in the treatment of hypertension by administering different antihypertensive drugs and preventive measures show no unanimous conclusion with regards to the behavior to be followed. It is worth noting that hypertension is a clearly established major cardiovascular risk factor ${ }^{1,2}$ and some clinical trials have shown the benefits obtained by lowering blood pressure below $140 / 90 \mathrm{mmHg}^{3}$ or more. In addition, there would be evidence that no control of the elevated blood pressure is the open-door to the development of cardiovascular disorders, often accompanied to organ damage. ${ }^{3-5}$

Starting from this assumption, there is evidence that blood pressure control is the main target of anti-hypertensive measures to prevent and, otherwise, reduce the cardiovascular complications of the hypertensive individuals.

\section{Large-scale trials and obtained results}

Large-scale trials to achieve a satisfactory control of blood pressure are continuously in progress and the large majority of them include both hypertension and hypertension-related disorders, ${ }^{4}$ which have been analyzed isolated or together. However, the discussion of all the trials, indeed, very numerous, is not the purpose of this review, whose target is to emphasize some results obtained and, also, the existing limits in their estimate. Essential hypertension, coronary artery disease in both hypertensive subjects and subjects without hypertension, rate and characteristics of stroke of the hypertensive individuals affected, and kidney alteration due to elevated blood pressure, including malignant hypertension are the main topics investigated by largescale clinical trials.

With regards to the clinical trials analyzing the outcome of hypertension and possible development of heart failure, and among these COPERNICUS ${ }^{6}$ seems to be one of the most emphasized, the unanimous conclusion is as major is blood pressure lowering anyway obtained as minor is the adverse effects of elevated blood pressure to determine cardiac complications. Generally, these trials investigated subjects, in a large majority, with hypertension, but also individuals with cardiovascular risk where elevated blood pressure did not show to be a determinant factor. The evidence clearly showed a major incidence of complications often accompanied with heart failure development in the hypertensive individuals.
PROGRESS ${ }^{7}$ is one of the most significant trial, which analyzed the relationship between hypertension and stroke. The study individuals enrolled were more than 6,000 , a largest number for a statistically reliable estimate. Obtained results recommended, in this case too, a significant reduction in blood pressure to control the outcome of cerebrovascular disorders. Coronary heart disease, including post-myocardial infarction, and hypertension have been widely investigated primarily by some trials. ${ }^{6,8-12}$ However, evidence indicated that also these trials enrolled hypertensive or no patients in the protocol study. The control of blood pressure was responsible of reduced cardiovascular events.

A great enthusiasm caused a very recent antihypertensive trial ${ }^{13}$ known as SPRINT, which analyzed a very intensive treatment of elevated values of blood pressure versus a standard approach to control this parameter. SPRINT In conclusion, targeting a systolic blood pressure of less than $120 \mathrm{~mm} \mathrm{Hg}$, as compared with less than $140 \mathrm{~mm} \mathrm{Hg}$, in patients at high risk for cardiovascular events, but without diabetes resulted in lower rates of fatal and nonfatal major cardiovascular events and death from any cause. However, some adverse events occurred significantly more frequently with the lower target.

\section{Conclusion}

In conclusion, did the antihypertensive clinical trials show benefits and/or limits? A double approach can be documented. It is worth noting that among the benefits identified by analyzing the antihypertensive trials undoubtedly a clear concept emerges: lowering blood pressure is the major target to be reached, and blood pressure values of $120 / 80 \mathrm{mmHg}$ or below should be maintained, if possible, particularly when other cardiovascular risk factors, primarily diabetes mellitus, affect the hypertensive individuals. Therefore, lowering blood pressure, anyway obtained, is the major determinant to achieve for reducing the rate of cardio- and cerebrovascular complications resulting from hypertension. ${ }^{15-18}$

On the contrary, the more evident limit hasn't found a drug able to lowering blood pressure in all the individuals treated since each subject can respond differently to the tested drug. Therefore, a personalized therapy, often difficult to establish, is to give to the hypertensive patient. As aforesaid, a large majority of large-scale trials does not identify a common drug lowering blood pressure significantly in all 
individuals. Therefore, the hypertensive patient needs to be addressed towards the most effective antihypertensive drug for himself and, then, use the same continuously at the time, even if the cost of the treatment could be markedly more elevated when compared to other antihypertensive substances at a less cost, but unable or scarcely effective to reduce blood pressure. ${ }^{19-22}$

Based on this assumption, my personal opinion is the large-scale trials enrolling the largest number of hypertensive individuals still need to establish how to control blood pressure independently by the cost-benefit ratio, which is a parameter carefully taken into account in the public health programs. ${ }^{23}$

\section{Acknowledgments}

None.

\section{Conflicts of interest}

Author declares there are no conflicts of interest.

\section{Funding}

None.

\section{References}

1. Lewington S, Clarke R, Qizilbash N, et al. Age-specific relevance of usual blood pressure to vascular mortality: a meta-analysis of individual data for one million adults in 61 prospective studies. Lancet. 2002;360:1903-1913.

2. Salvetti A, Versari D. Control of blood pressure in the Community: An unsolved problem. Curr Pharm Des. 2003;9(29):2375-2384.

3. Collins R, Peto R, McMahon S, et al. Blood pressure, stroke, and coronary heart disease. Part 2, Short-term reductions in blood pressure: overview of randomized drug trials in their epidemiological context. Lancet. 1990;335(8693):827-838.

4. Leone A, Landini L, Leone A. Epidemiology and costs of hypertensionrelated disorders. Curr Pharm Des . 2011;17(28):2955-2972.

5. Cohuet G, Struijker-Boudier H. Mechanisms of target organ damage caused by hypertension: therapeutic potential. Pharmacol Ther . 2006;111(1):81-98.

6. Packer M, Fowler MB, Roecker EB, et al. Effect of Carvedilol on the morbidity of patients with severe chronic heart failure. Results of the Carvedilol Randomized Cumulative Survival (COPERNICUS) Study. Circulation. 2002;106(17):2194-2199.

7. PROGRESS Collaborative Group. Randomised trial of a Perindoprilbased-blood pressure-lowering regimen among 6,105 individuals with previous stroke or transient ischaemic attack. Lancet. 2001;358(9287):1033-1041.

8. ALLHAT Officers and Coordinators for the ALLHAT Collaborative Research Group. Major outcomes in high-risk hypertensive patients randomized to angiotensin-converting enzyme inhibitor or calcium channel blocker vs diuretic. The Antihypertensive and LipidLowering Treatment to Prevent Heart Attack Trial (ALLHAT). JAMA. 2002;288(23):2981-2997.
9. Wing LMH, Reid CM, Ryan P, et al. A comparison of outcomes with angiotensin-converting enzyme inhibitors and diuretics for hypertension in the elderly. N Engl J Med . 2003;348(7):583-592.

10. Black HR, Elliot WS, Neaton JD, et al. Baseline characteristics and early blood pressure control in the CONVINCE Trial. Hypertension. 2001;37(1):12-18

11. Beta Blocker Heart Attack Trial Research Group (BHAT). A randomized trial of propranolol in patients with acute myocardial infarction. JAMA. 1982;247(12):1707-1714.

12. The NHLBI Working Group on Future Directions in Hypertension Treatment Trials. Major Clinical Trials of Hypertension What Should Be Done Next? Hypertension. 2005;46:1-6.

13. The SPRINT Research Group. A randomized trial of intensive versus standard blood-pressure control. N Engl J Med. 2015;373:2103-2116.

14. Leone A. The control of blood pressure worldwide: A glimmer of success. J Cardiol Curr Res. 2015;3(5):00117.

15. vanGijn J. The PROGRESS Trial: Preventing strokes by lowering blood pressure in patients with cerebral ischemia. Emerging therapies: Critique on an important advance. Stroke. 2002;33(1):319-320.

16. James PA, Oparil S, Carter BL, et al. 2014 evidence-based guideline for the management of high blood pressure in adults: report from the panel members appointed to the Eighth Joint National Committee (JNC 8). JAMA. 2014;311(5):507-520.

17. Mancia G, Fagard R, Narkiewicz K, et al. ESH/ESC guidelines for the management of arterial hypertension: the Task Force for the Management of Arterial Hypertension of the European Society of Hypertension (ESH) and of the European Society of Cardiology (ESC). J Hypertens. 2013;31(7):1281-1357.

18. Appel LJ, Wright JT Jr, Greene T, et al. Intensive blood-pressure control in hypertensive chronic kidney disease. $N$ Engl J Med. 2010;363(10):918-929.

19. Pedelty L, Gorelck PB. Chronic management of blood pressure after stroke. Hypertension. 2004;44(1):1-5.

20. MR Law, NJ Wald, JK Morris, et al. Value of low dose combination treatment with blood pressure lowering drugs: analysis of 354 randomised trials. BMJ . 2003;326:1427-1435.

21. Gradman AH, Basile JN, Carter BL, et al. Combination therapy in hypertension. JASH. 2010;4(2):42-50.

22. Wald DS, Law M, Morris JK, et al. Combination therapy versus monotherapy in reducing blood pressure: meta-analysis on 11,000 participants from 42 Trials. Am J Med . 2009;122(3):290-300.

23. Siegel JE, Weinstein MC, Russel LB, et al. Recommendations for reporting cost-effectiveness analyses. JAMA. 1996;276(16):1339-1341. 